\title{
Perbedaan Citra Diri dan Kesukaan Makanan Tertentu pada Siswa-Siswi Gizi Lebih dan Normal
}

\section{The Differences about Body Image and Favourite Food on Overweight and Normal Students}

Annisa Arifiana Lestari*1, Merryana Adriani ${ }^{1}$

\begin{abstract}
ABSTRAK
Latar Belakang: Citra diri dapat memprediksi munculnya depresi, gangguan makan dan kepercayaan diri. Menyukai suatu makanan secara berlebih dapat mempengaruhi status gizi individu.

Tujuan: Menganalisis perbedaan citra diri dan kesukaan makanan tertentu pada siswa-siswi gizi lebih dan normal di SMP Muhammdiyah 5 Pucang Surabaya.

Metode: Penelitian ini menggunakan desain studi case control dan melibatkan 42 responden yang dibagi menjadi 21 siswa-siswi dengan gizi lebih dan 21 murid dengan status gizi normal. Dilakukan pengukuran berat badan menggunakan digital body scale dan tinggi badan menggunakan microtoise untuk menilai status gizi. Wawancara dan pengisian kuesioner kepada responden untuk mengetahui karakteristik, citra diri dan kesukaan makanan tertentu. Teknik analisis data yang digunakan adalah uji korelasi Mann Whitney dengan $\mathrm{p}<0,05$.

Hasil: Pada kelompok gizi lebih terdapat 10 responden yang merasa citra dirinya obesitas dan ingin menurunkan berat badan $(47,62 \%)$. Lalu, pada kelompok status gizi normal terdapat 16 responden yang merasa citra dirinya adalah normal $(76,19 \%)$, menginginkan penurunan berat badan sebanyak 5 responden $(31,25 \%), 8$ responden $(50 \%)$ ingin memiliki berat badan tetap dan 3 responden $(18,75 \%)$ ingin menaikkan berat badannya dengan nilai $\mathrm{p}=0,000$. Untuk kesukaan makanan pada bahan makanan tertentu, kelompok gizi lebih dan normal lebih menyukai minuman berpemanis $(38,1 \%$ dan $61,9 \%)$ dengan nilai $\mathrm{p}=0,037$.
\end{abstract}

Kesimpulan: Terdapat perbedaan citra diri dan kesukaan makanan tertentu pada kelompok gizi lebih dan normal.

Kata kunci: remaja, citra diri, kesukaan makanan, status gizi

\begin{abstract}
Background: Body image could express such as depression, eating disorder and self esteem. If someone like to ate some specific food too much it can affected to nutrition status.

Objectives: This study aimed to analyze of the difference of body image and favourite food between students with overweight and normal at SMP Muhammadiyah 5 Pucang Surabaya.

Methods: The design of this study was case control involving 42 samples with 21 case sampels for overweight and 21 control sampels for normal student. The questioners were about body height and weight, data identity, body image and food preferences. Data were analyzed using Mann Whitney with $p<0,005$.

Results: There were 10 sampels in overweight group who felt they were obese and wanted to lose weight. In normal group there were 16 sampels who felt their body image was normal and 5 sampels in this group wanted to lose weight too, and the score for the $p$ value $=0,000$. As for food preferences, the overweight groups was more like to ate fried food (28,6\%), while the normal group more preferred to ate sweetened foods and drinks $(61,9 \%)$ with $p$ value $=0,037$.
\end{abstract}

Conclusions: In conclusion there were differences of body image and favourite food between two groups

Keywords: adolescent, body image, favourite food, nutrition status

\footnotetext{
*Koresponden:

adrianimerryanafkmunair@gmail.com

${ }^{1}$ Merryana Adriani

Departemen Gizi Kesehatan, Fakultas Kesehatan Masyarakat, Universitas Airlangga, Kampus C, Mulyorejo, 60115,

Surabaya, Jawa Timur, Indonesia
} 


\section{PENDAHULUAN}

Usia remaja merupakan transisi antara masa kanak-kanak dan dewasa sering digambarkan sebagai waktu turbulensi dan stres bagi kaum muda. Pada masa transisi tersebut terjadi pula perubahan yang berlangsung cepat dalam hal pertumbuhan fisik, kognitif,dan psikososial atau tingkah laku(Susetyowati, 2016). Masalah gizi pada usia remaja sangat beragan salah satunya masalah gizi lebih. Pada kategori remaja umur 13-15 tahun, prevalensi gizi lebih ditemukan sebesar 10,8\% yang terdiri dari 8,3\% gemuk, dan 2,5\% sangat gemuk (obesitas)(Kementerian Kesehatan RI, 2013).

Pada remaja, citra diri merupakan hal yang sangat dipedulikan. Citra diri meliputi citra diri positif dan citra diri negatif. Citra diri positif adalah keadaan dimana individu merasa puas dengan keadaan tubuhnya sedangkan citra diri negatif yaitu keadaan dimana individu tidak puas terhadap keadaan tubuhnya(Willianto, 2017). Pada penelitian sebelumnya yang dilakukan pada siswi usia 13-15 tahun di SMPK Santa Agnes Surabaya, terdapat 55,6\% responden yang memiliki citra diri negatif. Pada siswi overweight, terdapat 72,2\% siswi yang memiliki citra diri negatif sedangkan pada siswi non overweight, 61,1\% siswi memiliki citra diri positif(Wati and Sumarmi, 2017). Citra diri terhadap diri sendiri dan tingkat stres dapat mempengaruhi pola makan individu(Gattario, 2013).

Pola konsumsi makan tidak teratur, sering tidak makan pagi dan siang serta sering jajan merupakan contoh kebiasaan makan dengan kualitas makanan yang tidak baik(Anindita, 2017). Pemilihan makanan dipengaruhi faktor internal berupa faktor biologis dan psikologi serta faktor eksternal seperti teman, keluarga, dan lingkungan sosial(Chan and Woo, 2010; Gattario, 2013). Berdasar penelitian yang dilakukan pada siswi kelas VIII SMP Al Islam 1 Surakarta, 51,7\% pola makan responden termasuk tidak normal yaitu makan tidak teratur dan cenderung membatasi konsumsi makanan karena ketidakpuasan terhadap keadaan tubuhnya(Verawati, 2015).

Penelitian ini bertujuan untuk menganalisis perbedaan citra diri dan kesukaan makanan tertentu pada siswasiswi dengan status gizi lebih dan normal di SMP Muhammadiyah 5 Pucang Surabaya. Lokasi ini dipilih karena berada di perkotaan yang di sekitarnya banyak terdapat penjual makanan yang mungkin dapat mempengaruhi status gizi pada remaja. Selain itu, belum pernah dilakukan penelitian terkait gizi remaja di sekolah ini sehingga perlu dilakukan penelitian pada siswa-siswi terkait status gizinya.

\section{METODE}

Penelitian ini menggunakan desain studi case control. Teknik pengambilan sampel menggunakan simple random sampling dengan jumlah sampel 42 yang terbagi menjadi dua kelompok yaitu kelompok kasus atau gizi lebih dan kelompok kontrol atau gizi normal. Kriteria inklusi responden pada penelitian ini adalah siswa-siswi kelas VIII yang berusia 13-15 tahun, memiliki status gizi lebih dan normal serta bersedia menjadi responden selama penelitian berlangsung.

Penelitian dilaksanakan pada bulan Maret 2019 hingga April 2019. Variabel bebas pada penelitian ini yaitu citra diri dan kesukaan makanan tertentu, sedangkan variabel terikat yaitu status gizi yang terdiri dari gizi lebih dan normal. Untuk mengetahui makanan kesukaan tertentu dilakukan pengisian SQ FFQ. Instrumen lain yang digunakan adalah kuesioner data identitas untuk memperoleh data mengenai karakteristik responden yang terdiri dari usia, besar uang saku, pendidikan orang tua, pekerjaan orang tua, dan aktivitas fisik. Uji statistik menggunakan uji beda Mann Whitney dengan $\mathrm{p}<0,05$ untuk menganalisis perbedaan antara citra diri dan kesukaan makanan tertentu dengan status gizi.

Penelitian ini telah memperoleh izin dari Komisi Etik Fakultas Keperawatan Universitas Airlangga dengan No: 202/EA/KEPK/2019 tanggal 14 Agustus 2019. 


\section{HASIL DAN PEMBAHASAN}

Tabel 1. Distribusi Karakteristik Responden di SMP Muhammadiyah 5 Pucang Surabaya Tahun 2019

\begin{tabular}{|c|c|c|c|c|}
\hline \multirow{3}{*}{ Karakteristik } & \multicolumn{4}{|c|}{ Jumlah Responden } \\
\hline & \multicolumn{2}{|c|}{ Gizi Lebih } & \multicolumn{2}{|c|}{ Normal } \\
\hline & $\mathbf{n}$ & $\%$ & $\mathbf{n}$ & $\%$ \\
\hline \multicolumn{5}{|l|}{ Usia } \\
\hline 13 tahun & 0 & 0,0 & 0 & 0,0 \\
\hline 14 tahun & 21 & 50,0 & 21 & 50,0 \\
\hline 15 tahun & 0 & 0,0 & 0 & 0,0 \\
\hline Total & 21 & 100,0 & 21 & $\mathbf{1 0 0 , 0}$ \\
\hline \multicolumn{5}{|l|}{ Jenis Kelamin } \\
\hline 1. Laki-laki & 14 & 67,0 & 12 & 57,0 \\
\hline 2. Perempuan & 7 & 33,0 & 9 & 43,3 \\
\hline Total & 21 & 100,0 & 21 & 100,0 \\
\hline \multicolumn{5}{|l|}{ Uang Saku } \\
\hline \multicolumn{5}{|c|}{ Membelanjakan semua uang saku } \\
\hline$\geq \operatorname{Rp} 25.000$ & 2 & 9,5 & 5 & 23,8 \\
\hline$<\operatorname{Rp} 25.000$ & 5 & 23,8 & 9 & 42,9 \\
\hline $\operatorname{Rp} 0$ & 1 & 4,8 & 2 & 9,5 \\
\hline \multicolumn{5}{|c|}{$\begin{array}{l}\text { Membelanjakan sebagian uang } \\
\text { saku }\end{array}$} \\
\hline$\geq \operatorname{Rp} 25.000$ & 11 & 52,4 & 4 & 19 \\
\hline$<\operatorname{Rp} 25.000$ & 2 & 9,5 & 1 & 4,8 \\
\hline $\operatorname{Rp} 0$ & 0 & 0,0 & 0 & 0,0 \\
\hline Total & 21 & 100,0 & 21 & 100,0 \\
\hline \multicolumn{5}{|l|}{ Pendidikan Orang Tua } \\
\hline \multicolumn{5}{|l|}{ Ayah } \\
\hline Perguruan tinggi & 16 & 76,1 & 17 & 80,9 \\
\hline SMA & 3 & 14,3 & 3 & 14,3 \\
\hline SMP & 1 & 4,8 & 1 & 4,8 \\
\hline $\mathrm{SD}$ & 1 & 4,8 & 0 & 0,0 \\
\hline Tidak Tamat SD & 0 & 0,0 & 0 & 0,0 \\
\hline Total & 21 & 100,0 & 21 & 100,0 \\
\hline \multicolumn{5}{|l|}{ Ibu } \\
\hline Perguruan tinggi & 18 & 85,7 & 15 & 71,4 \\
\hline SMA & 3 & 14,3 & 3 & 14,3 \\
\hline SMP & 0 & 0,0 & 3 & 14,3 \\
\hline $\mathrm{SD}$ & 0 & 0,0 & 0 & 0,0 \\
\hline Tidak Tamat SD & 0 & 0,0 & 0 & 0,0 \\
\hline Total & 21 & 100 & 21 & 100,0 \\
\hline \multicolumn{5}{|l|}{ Pekerjaan Orang Tua } \\
\hline \multicolumn{5}{|l|}{ 1. Ayah } \\
\hline PNS & 0 & 0,0 & 1 & 4,8 \\
\hline TNI & 1 & 4,8 & 2 & 9,5 \\
\hline Swasta & 12 & 57,1 & 10 & 47,6 \\
\hline Wiraswasta & 7 & 33,3 & 8 & 38,1 \\
\hline Petani & 0 & 0,0 & 0 & 0,0 \\
\hline Pensiun & 0 & 0,0 & 0 & 0,0 \\
\hline Tidak bekerja & 1 & 4,8 & 0 & 0,0 \\
\hline Lain-lain & 0 & 0,0 & 0 & 0,0 \\
\hline Total & 21 & 100,0 & 21 & 100,0 \\
\hline \multicolumn{5}{|l|}{ 2. Ibu } \\
\hline PNS & 1 & 4,8 & 0 & 0,0 \\
\hline TNI & 1 & 4,8 & 0 & 0,0 \\
\hline Swasta & 10 & 47,8 & 8 & 38,1 \\
\hline
\end{tabular}


Lanjutan.

Tabel 1. Distribusi Karakteristik Responden di SMP Muhammadiyah 5 Pucang Surabaya Tahun 2019

\begin{tabular}{|c|c|c|c|c|}
\hline \multirow{3}{*}{ Karakteristik } & \multicolumn{4}{|c|}{ Jumlah Responden } \\
\hline & \multicolumn{2}{|c|}{ Gizi Lebih } & \multicolumn{2}{|c|}{ Normal } \\
\hline & $\mathbf{n}$ & $\%$ & $\mathbf{n}$ & $\%$ \\
\hline \multicolumn{5}{|l|}{ Pekerjaan Orang Tua } \\
\hline Wiraswasta & 4 & 19,0 & 4 & 19,0 \\
\hline Petani & 0 & 0,0 & 0 & 0,0 \\
\hline Pensiun & 0 & 0,0 & 0 & 0,0 \\
\hline Tidak bekerja & 6 & 28,6 & 8 & 38,1 \\
\hline Lain-lain & 0 & 0,0 & 1 & 4,8 \\
\hline Total & 21 & 100,0 & 21 & 100,0 \\
\hline \multicolumn{5}{|l|}{ Status Gizi } \\
\hline Gizi lebih & 21 & 100,0 & 0 & 0,0 \\
\hline Normal & 0 & 0,0 & 21 & 100,0 \\
\hline Total & 21 & 100,0 & 21 & 100,0 \\
\hline \multicolumn{5}{|l|}{ Aktivitas Fisik } \\
\hline Sangat ringan & 10 & 47,6 & 14 & 66,7 \\
\hline Ringan & 7 & 33,3 & 3 & 14,3 \\
\hline Sedang & 3 & 14,3 & 3 & 14,3 \\
\hline Berat & 1 & 4,8 & 1 & 4,7 \\
\hline Total & 21 & 100,0 & 21 & 100,0 \\
\hline
\end{tabular}

Hasil pada Tabel 1 menunjukkan karakteristik responden, untuk usia seluruh responden berusia 14 tahun dan duduk dikelas VIII. Terdapat 14 responden (67\%) laki-laki dan 7 responden (33\%) perempuan pada kelompok gizi lebih, sedangkan pada kelompok gizi normal terdiri dari 12 responden (57\%) laki-laki dan 9 responden (43\%) perempuan. Beberapa faktor yang dapat mempengaruhi terjadinya overweight atau gizi lebih yaitu seperti aktivitas fisik, pola makan, jenis makanan, poris makanan yang dimakan dalam satu hari(Husain, Tendean and Queljoe, 2015). Pada kelompok gizi lebih yang menerima uang saku sebanyak $\geq R p 25.000$ terdapat 11 responden (52,4\%) membelanjakan sebagian uang saku nya, sedangkan pada responden yang menerima uang saku sebanyak $<\mathrm{Rp} 25.000$ terdapat 5 responden $(23,8 \%)$ cenderung membelanjakan semua uang saku yang diterima. Sama halnya dengan kelompok gizi normal, dimana yang menerima uang saku $\geq R p 25.000$ sebanyak 4 responden (19\%) hanya menggunakan sebagian uang saku untuk dibelanjakan, sedangkan pada responden lain di dalam kelompok gizi normal ini yang mendapatkan uang saku <Rp 25.000 sebanyak 9 responden $(42,9 \%)$ cenderung membelanjakan semua uang sakunya. Dalam penelitian sebelumnya dinyatakan bahwa tidak adanya perbedaan jumlah saku antara kelompok dengan status gizi overweight dan non overweight, hal ini disebabkan karena seluruh murid membelanjakan pada jenis makanan yang sama di kantin sekolah(Astuty, 2016). Pada karakteristik pendidikan ayah pada kelompok gizi lebih 16 orang $(76,1 \%)$ dan pada kelompok gizi normal terdapat 17 orang $(80,9 \%)$ yang memiliki pendidikan terakhir hingga jenjang perguruan tinggi. Pada pendidikan terakhir ibu dari kelompok gizi lebih sebanyak 18 orang $(85,7 \%)$ dan pada kelompok gizi normal sebanyak 15 orang $(71,4 \%)$ menyelesaikan pendidikan terakhir hingga jenjang perguruan tinggi. Pekerjaan yang dilakukan oleh ayah dari kedua kelompok yaitu sebagai karyawan pekerja swasta sebanyak 12 orang $(57,1 \%)$ untuk kelompok gizi lebih dan 10 orang $(47,6 \%)$ pada gizi normal. Sedangkan pada pekerjaan yang dilakukan oleh ibu dari kedua kelompok yaitu sebagai pekerja swasta sebanyak 10 orang (47,8\%) pada kelompok gizi lebih dan 8 orang $(38,1 \%)$. Pada penelitian sebelumnya menyatakan bahwa tidak ada hubungan yang bermakna antara pekerjaan dari ibu dan ayah dengan status gizi responden, hal tersebut disebabkan karena status gizi adalah hasil dari dampak langsung masuknya makanan dengan jangka waktu yang tidak sebentar, maka itu faktor makananlah yang berpengaruh pada perubahan status gizi(Putri, H and Maemunah, 2017). Hasil dari analisis aktivitas fisik menunjukkan bahwa kelompok gizi lebih cenderung memiliki aktivitas fisik sangat ringan (47,6\%), sedangkan pada kelompok status gizi normal juga cenderung memiliki aktivitas fisik sangat ringan $(66,7 \%)$. Penelitian sebelumnya menyatakan bahwa terdapat perbedaan mengenai aktivitas fisik antara kelompok obesitas dan non obesitas, hal ini disebabkan interaksi antara makan banyak namun sedikit melakukan aktivitas fisik, sehingga energi yang terbakar sedikit(Suryaputra and Nadhiroh, 2012). 
Tabel 2. Distribusi Citra Diri di SMP Muhammadiyah 5 Pucang Surabaya Tahun 2019

\begin{tabular}{|c|c|c|c|c|c|c|c|c|c|c|}
\hline \multirow{2}{*}{$\begin{array}{c}\text { Status } \\
\text { Gizi }\end{array}$} & \multirow{2}{*}{$\begin{array}{l}\text { Citra } \\
\text { Diri }\end{array}$} & \multicolumn{2}{|c|}{ Jumlah } & \multicolumn{2}{|c|}{$\begin{array}{c}\text { Ingin BB } \\
\text { Turun }\end{array}$} & \multicolumn{2}{|c|}{$\begin{array}{c}\text { Ingin BB } \\
\text { Tetap }\end{array}$} & \multicolumn{2}{|c|}{$\begin{array}{c}\text { Ingin BB } \\
\text { Naik }\end{array}$} & \multirow[t]{2}{*}{ p value } \\
\hline & & $\mathbf{n}$ & $\%$ & $\mathbf{n}$ & $\%$ & $\mathbf{n}$ & $\%$ & n & $\%$ & \\
\hline \multirow{3}{*}{ Gizi Lebih } & Kurus & 1 & 2,10 & 0 & 0,00 & 0 & 0,00 & 1 & 4,76 & \multirow{8}{*}{$\mathbf{0 , 0 0 0}$} \\
\hline & Normal & 10 & 48,95 & 9 & 42,85 & 1 & 4,76 & 0 & 0,00 & \\
\hline & Obesitas & 10 & 48,95 & 10 & 47,61 & 0 & 0,00 & 0 & 0,00 & \\
\hline Total & & 21 & 100,00 & 19 & 90,11 & 1 & $\mathbf{4 , 7 6}$ & 1 & 4,76 & \\
\hline \multirow{3}{*}{ Normal } & Kurus & 5 & 23,81 & 0 & 0,00 & 0 & 0,00 & 5 & 23,81 & \\
\hline & Normal & 16 & 76,19 & 5 & 23,81 & 8 & 38,09 & 3 & 14,28 & \\
\hline & Obesitas & 0 & 0,00 & 0 & 0,00 & 0 & 0,00 & 0 & 0,00 & \\
\hline Total & & 21 & 100,00 & 5 & 23,81 & 8 & 38,09 & 8 & 38,09 & \\
\hline
\end{tabular}

Tabel 2 menyajikan distribusi citra diri responden. Pada kelompok kasus atau responden kelompok gizi lebih, terdapat masing-masing 10 responden yang memiliki citra diri normal dan obesitas $(48,95 \%)$. Sebanyak 9 dari 10 responden kelompok gizi lebih yang memiliki citra diri normal $(42,85 \%)$ ingin menurunkan berat badannya sedangkan 1 responden lainnya ingin berat badannya tetap (4,76\%). Sedangkan, seluruh responden kelompok gizi lebih yang memiliki citra diri obesitas ingin menurunkan berat badannya. Pada kelompok kontrol atau kelompok gizi normal, 16 responden memiliki citra diri normal $(76,19 \%)$ sedangkan 5 responden lain memiliki citra diri kurus $(23,81 \%)$. Pada kelompok gizi normal yang memiliki citra diri normal, 5 dari 16 responden menginginkan penurunan berat badan, 3 responden lain menginginkan peningkatan berat badan sedangkan 8 responden sisanya tidak menginginkan perubahan berat badan (ingin berat badan tetap). Seluruh responden kelompok gizi normal yang memiliki citra diri kurus menginginkan peningkatan berat badan. Berdasarkan hasil uji beda yang dilakukan antara kelompok gizi lebih dan gizi normal, nilai $\mathrm{p}=0,0000$ yang berarti terdapat perbedaan citra diri pada kelompok gizi lebih dan gizi normal. Hasil tersebut sejalan dengan penelitian sebelumnya yang menunjukkan terdapat perbedaan citra tubuh pada remaja putra berstatus gizi normal dengan obesitas ( $\mathrm{p}=0,0000)$ (Ramadhani, 2014). Begitu pula dengan hasil penelitian sebelumnya yang dilakukan di SMPK Santa Agnes Surabaya yang menunjukkan bahwa terdapat perbedaan bermakna terhadap citra tubuh antara siswi overweight dengan non overweight $(\mathrm{p}=0,044)(\mathrm{Wati}$ and Sumarmi, 2017). Dalam penelitian lain menyatakan bahwa terdapat hubungan mengenai body image dan pola makan remaja, pada murid yang memiliki body image positif maka cenderung memiliki pola makan yang baik(Chairiah, 2012). Penelitian lain dengan responden murid SMP menunjukkan adanya hubungan dan perbedaan antara bentuk tubuh dan status gizi, dimana murid yang berstatus gizi normal dan berstatus gizi lebih memiliki bentuk tubuh normal sebagai bentuk yang ideal(Lestari, 2014). Namun pada penelitian lain, siswa yang berstatus gizi normal lebih banyak memiliki citra tubuh positif dan merasa puas dengan bentuk tubuhnya, sedangkan pada status gizi lebih lebih banyak memiliki citra tubuh negatif dan merasa tidak puas dengan bentuk tubuhnya (Veria and Fani, 2014; Setyawati and Setyowati, 2015; Nugroho, 2018). Hasil penelitian ini tidak sejalan dengan penelitian sebelumnya yang menyatakan bahwa tidak ada perbedaan antara citra tubuh pada responden(Bening, 2014). Penilitian yang dilakukan di Jayapura menunjukkan adanya hubungan antara body image dengan status gizi, dimana penilaian bentuk tubuh yang tidak ideal didasarkan pada pendapat pribadi, sebagian besar mempunyai bentuk tubuh kurus dan menurut mereka bentuk tubuh ideal adalah yang sesuai dengan berat badan(Sada, Hadju and Dachlan, 2012). Pandangan citra tubuh terutama pada siswi atau perempuan masih mengikuti pendapat dari lingkungan sekitar, sehingga terkadang "image" yang tergambar adalah cantik sama dengan kurus(Fajri, Febry and Mutahar, 2014).

Tabel 3. Distribusi Kesukaan Makanan Tertentu Di SMP Muhammadiyah 5 Pucang Surabaya Tahun 2019

\begin{tabular}{|c|c|c|c|c|c|}
\hline \multirow{3}{*}{ Bahan Makanan } & \multicolumn{4}{|c|}{ Status Gizi } & \multirow{3}{*}{$p$ value } \\
\hline & \multicolumn{2}{|c|}{ Gizi Lebih } & \multicolumn{2}{|c|}{ Normal } & \\
\hline & $\mathbf{n}$ & $\%$ & $\mathbf{n}$ & $\%$ & \\
\hline Makanan pokok & 0 & 0,0 & 0 & 0,0 & \\
\hline Lauk hewani & 0 & 0,0 & 0 & 0,0 & \\
\hline Lauk nabati & 0 & 0,0 & 2 & 9,5 & \\
\hline Sayuran & 4 & 19 & 1 & 4,8 & $\mathbf{0 , 0 3 7}$ \\
\hline Buah & 1 & 4,8 & 2 & 9,5 & \\
\hline Snack & 6 & 28,6 & 5 & 23,8 & \\
\hline Minuman berpemanis & 8 & 38,1 & 13 & 61,9 & \\
\hline Total & 21 & $\mathbf{1 0 0 , 0}$ & 21 & 100,0 & \\
\hline
\end{tabular}


Tabel 3 menampilkan distribusi kesukaan makanan tertentu pada responden. Pada kelompok gizi lebih dan gizi normal, minuman berpemanis disukai oleh sebagian besar responden dengan persentase masing-masing 38,1\% untuk kelompok gizi lebih dan 61,9\% untuk kelompok gizi normal. Dari hasil uji beda ditemukan perbedaan kesukaan makanan tertentu pada kelompok gizi lebih dan gizi normal dengan nilai $\mathrm{p}=0,037$. Preferensi pada saat memilih makanan dapat dipengaruhi dari pengalaman yang pernah dilalui baik yang menyenangkan maupun yang tidak menyenangkan, sehingga seseorang memiliki sikap ketidak sukaan maupun suka terhadap suatu makanan, preferensi juga dapat diartikan sebagai derajat suka dan/atau tidak suka terhadap suatu makanan dan dapat mempengaruhi daya konsumsi seorang konsumen(Sinaga et al., 2012). Pemilihan dari kesukaan jajanan makanan tertentu seperti snack dan minuman berpemanis merupakan salah satu contoh jajanan yang tidak sehat, maka dari itu perlunya pemilihan jajanan yang sehat akan berdampak pada peningkatan kesehatan tubuh(Saputri, Kristiawati and Krisnana, no date). Pemilihan makanan dengan pola makan yang baik dapat membantu mencapai status gizi yang baik(Intantiyana, Widajanti and Rahfiludin, 2018). Penelitian sebelumnya menyatakan terdapat hubungan dari perilaku makan orang tua dengan adanya perilaku kesulitan makan pada anak, apabila orang tua memiliki perilaku makan tidak baik, maka anak lebih berpeluang untuk memiliki atau mengalami kesulitan makan(Kesuma, Novayelinda and Sabrian, 2015).

\section{KESIMPULAN}

Pada penelitian ini menunjukkan adanya perbedaan antara citra diri dan kesukaan makanan tertentu dengan status gizi pada siswa-siswi di SMP Muhammadiyah 5 Pucang Surabaya.

\section{ACKNOWLEDGEMENT}

Penulis berterima kasih kepada seluruh responden penelitian, Badan Kesatuan Bangsa dan Politik Kota Surabaya, Dinas Pendidikan Kota Surabaya, SMP Muhammadiyah 5 Pucang Surabaya yang telah memberikan ijin dan membantu berjalannya proses penelitian ini, enumerator, dosen Program Studi Gizi Fakultas Kesehatan Masyarakat Universitas Airlangga serta staff, khususnya kepada dosen pembimbing sehingga terselesaikannya penelitian ini.

\section{REFERENSI}

Anindita, D. P. (2017) Hubungan Body Image, Kebiasaan Makan, dan Pengetahuan Gizi dengan Status Gizi pada Siswi SMK Kesehatan Dwi Putri Husada. Institut Pertanian Bogor.

Astuty, R. T. (2016) „Perbedaan Asupan Serat dan Besar Uang Saku antara Status Overweight dan Non Overweight

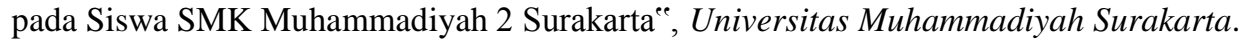

Bening, S. (2014) „Perbedaan Pengetahuan Gizi, Body Image, Asupan Energi dan Status Gizi pada Mahasiswi Gizi dan Non Gizi Universitas Diponegoro "e, Journal of Nutrition College, 3(4), pp. 715-722.

Chairiah, P. (2012) Hubungan Gambaran Body Image dan Pola Makan Remaja Putri di SMAN 38 Jakarta,Universitas Indonesia. Universitas Indonesia.

Chan, R. S. M. and Woo, J. (2010) „Prevention of overweight and obesity: How effective is the current public health approach $^{\text {ee }}$ International Journal of Environmental Research and Public Health, 7(3), pp. 765-783. doi: 10.3390/ijerph7030765.

Fajri, A. A., Febry, F. and Mutahar, R. (2014) „BODY IMAGE DESCRIPTION AND RELATING FACTORS TO NUTRITIONAL STATUS OF ADOLESCENT GIRLS SMAN 17 PALEMBANG AND SMA NURUL IMAN

PALEMBANG IN THE YEAR OF 2009“e, Jurnal Ilmu Kesehatan Masyarakat, 5(2), pp. 127-133.

Gattario, K. H. (2013) BODY IMAGE IN ADOLESCENCE : Through the Lenses of Culture, Gender, and PositivePsychology. Gothenburg: University of Gothenburg.

Husain, A., Tendean, L. and Queljoe, E. De (2015), „PENGARUH KELEBIHAN BERAT BADAN / OVERWEIGHT TERHADAP TERJADINYA DISFUNGSI SEKSUAL PRIA“e, Jurnal e-Biomedik, 3(3), pp. 782-785. doi: 10.35790/ebm.3.3.2015.10143.

Intantiyana, M., Widajanti, L. and Rahfiludin, M. Z. (2018) „HUBUNGAN CITRA TUBUH, AKTIVITAS FISIK DAN PENGETAHUAN GIZI SEIMBANG DENGAN KEJADIAN OBESITAS PADA REMAJA PUTRI GIZI

LEBIH DI SMA NEGERI 9 KOTA SEMARANGee, Jurnal Kesehatan Masyarakat (e-Journal), 6(5), pp. $404-412$. Kementerian Kesehatan RI (2013) Riset Kesehatan Dasar 2013. Jakarta.

Kesuma, A., Novayelinda, R. and Sabrian, F. (2015) „Faktor-faktor yang berhubungan dengan perilaku kesulitan makan anak prasekolahe, Jurnal Online Mahasiswa, 2(2), pp. 953-961.

Lestari, W. D. (2014) KEBIASAAN MAKAN DAN PERSEPSI BODY IMAGE PADA SISWA SMP BERSTATUS GIZI

LEBIH DAN NORMAL. Institut Pertanian Bogor.

Nugroho, R. F. (2018) Hubungan stres psikososial, persepsi bentuk tubuh, eating disorder dan pola makan dengan status gizi pada remaja putri. Universitas Sebelas Maret. 
Putri, R. M., H, W. R. and Maemunah, N. (2017) „Kaitan Pendidikan,Pekerjaan Orang Tua Dengan Status Gizi Anak Pra Sekolahe, Care : Jurnal Ilmiah Ilmu Kesehatan, 5(2), pp. 231-245.

Ramadhani, I. D. (2014) „Perbedaan Citra Tubuh Berdasarkan Status Gizi Remaja Putra

Sada, M., Hadju, V. and Dachlan, D. M. (2012) „HUBUNGAN BODY IMAGE, PENGETAHUAN GIZI SEIMBANG, DAN AKTIFITAS FISIK TERHADAP STATUS GIZI MAHASISWA POLITEKNIK KESEHATAN

JAYAPURA ${ }^{e}$, Media Gizi Masyarakat Indonesia, 2(1), pp. 44-48.

Saputri, L. O., Kristiawati and Krisnana, I. (no date) „PENINGKATAN PENGETAHUAN DAN SIKAP DALAM PEMILIHAN JAJANAN SEHAT MENGGUNAKAN ALAT PERMAINAN EDUKATIF ULAR TANGGA ${ }^{c e}$, pp. $1-10$.

Setyawati, V. A. V. and Setyowati, M. (2015) „KARAKTER GIZI REMAJA PUTRI URBAN DAN RURAL DI

PROVINSI JAWA TENGAH ${ }^{e}$, Jurnal Kesehatan Masyarakat. Department of Drama, Dance and Music, Semarang State University, 11(1), pp. 43-52. doi: 10.15294/kemas.v11i1.3463.

Sinaga, T. et al. (2012) „Kualitas sarapan menu sepinggan, daya terima, tingkat kesukaan, dan status gizi siswa sekolah dasar"e, Teknologi dan Kejuruan, 35(1), pp. 93-102.

Suryaputra, K. and Nadhiroh, S. R. (2012) „Perbedaan Pola Makan Dan Aktivitas Fisik Antara Remaja Obesitas Dengan Non Obesitas ${ }^{\text {ee }}$ Makara, Kesehatan, 16(1), pp. 45-50. Available at: http://journal.ui.ac.id/index.php/health/article/view/1301.

Susetyowati (2016) Ilmu Gizi Teori dan Aplikasi: Gizi Remaja. Jakarta: Penerbit Buku Indonesia EGC. Verawati, R. (2015) „Hubungan antara Body Image dengan Pola Makan dan Status Gizi Remaja Putri di SMP AlIslam 1 Surakarta ${ }^{e e}$.

Veria, V. A. and Fani, T. (2014) Body Image, Pengetahuan Gizi, Perilaku Makan sebagai Prediktor Status Gizi danDasar Pendidikan Gizi pada Remaja Putri. Universitas Dian Nuswantoro.

Wati, D. K. and Sumarmi, S. (2017) „Body Image Among Overweight and Non overweight Adolescent Girls : A Cross Sectional Studyee, Amerta Nutrition, 1(4), pp. 398-405. doi: 10.20473/amnt.v1.i4.2017.398-405.

Willianto, D. A. (2017) Hubungan antara Konsep Diri dan Citra Tubuh pada Perempuan Dewasa Awal, UniversitasSanata Dharma. Universitas Sanata Dharma. 